\title{
Bumetanide: Potent New "Loop" Diuretic
}

\author{
M. J. ASBURY, P. B. B. GATENBY, S. O'SULLIVAN, E. BOURKE
}

\section{Subjects and Methods}

\section{Summary}

Bumetanide, a pharmacologically new diuretic, was evaluated in 27 subjects. Its onset of action was within 30 minutes with a peak at 90 minutes and a total duration of action of about 270 minutes. In a controlled study in oedematous patients it was equipotent with frusemide at one-fortieth the molar dosage and did not differ from frusemide with regard to its pattern of electrolyte excretion. On continuous oral administration for eight days it produced effective diuresis with minimal alteration in biochemical and haematological status. The only adverse effect was gastric discomfort in one patient.

\section{Introduction}

Bumetanide is a potent new diuretic agent with structural features not shared by other available diuretics. In contrast to frusemide and the thiazides, which are derived from sulphanilamide, bumetanide is a derivative of metanilamide and has the further important difference of the presence of a phenoxy group (Feit, 1971) (Fig. 1). In the dog it is substantially more active

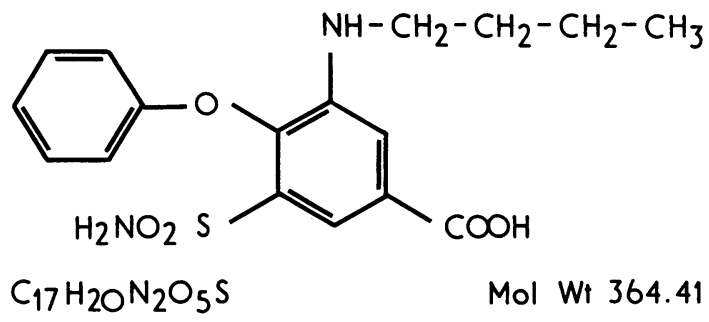

FIG. 1-Structural formula of bumetanide, 3-n-butylamino4-phenoxy-5-sulphamoyl benzoic acid.

than frusemide although, unlike the latter drug (Brenner et al., $1968,1969)$, it is practically ineffective in the rat ( $\varnothing_{\text {stergaard, }}$ personal communication, 1972). In healthy volunteers we observed a fall in both $\mathrm{C}_{\mathrm{H}_{2} \mathrm{O}}$ during water diuresis and in $\mathrm{Tc}_{\mathrm{H}_{2} \mathrm{O}}$ during hydropenia consistent with a major action on the ascending limb of Henle's loop (Bourke et al., 1972). A transient decrease in phosphate reabsorption also occurred, suggesting an additional action on the proximal tubule.

In this communication we present volumetric and biochemical results from 27 subjects, including four healthy volunteers and patients with oedema of various aetiologies. Bumetanide has a rapid onset and short duration of action. In oedematous patients its potency was equal to that of frusemide at one-fortieth the molar dose. On continuous administration for eight days it was an effective natriuretic agent in patients with both adequate and poor renal function, without significant alteration in plasma electrolytes, acid-base balance, glucose tolerance, or creatinine clearance.

Department of Clinical Medicine, Trinity College, Dublin, and the Federated Dublin Voluntary Hospitals

M. J. ASBURY, M.B., B.CH., Research Fellow

P. B. B. GATENBY, M.D., F.R.C.P., Professor of Medicine

S. O'SULLIVAN, B.SC., Research Assistant

E. BOURKE, M.B., M.R.C.P., Lecturer in Medicine

The 27 subjects studied were distributed as follows:

(a) Four healthy volunteers in whom the acute effects of the drug on urinary volume and electrolyte content were studied.

(b) Eighteen oedematous patients (14 men and 4 women) age $38-69$, most of whom were admitted to hospital as a result of failure to control oedema adequately. This group comprised five patients with cor pulmonale, five with ischaemic heart disease, four with chronic renal failure and hypertensive cardiovascular disease, and four others suffering from the nephrotic syndrome, alcoholic cardiomyopathy, atrial fibrillation, and rheumatic valvular disease. All patients were placed on a $5-\mathrm{g}$ salt diet, which was otherwise unrestricted. After at least 48 hours in hospital withoui diuretic therapy each patient was assigned randomly to one of the six dosage rotations shown in Table I. Three of these patients were

TABLE I-Dosage Rotations to which the Patients were Randomly Assigned

\begin{tabular}{l|l|l}
\hline Day 1 & Day 2 & Day 3 \\
\hline Placebo & Frusemide & Bumetanide \\
Placebo & Bumetanide & $\begin{array}{l}\text { Frusemide } \\
\text { Frusemide }\end{array}$ \\
$\begin{array}{l}\text { Frusemide } \\
\text { Bumetanide }\end{array}$ & $\begin{array}{l}\text { Placebo } \\
\text { Bumetanide }\end{array}$ \\
& $\begin{array}{l}\text { Placebo } \\
\text { Placebo }\end{array}$ & $\begin{array}{l}\text { Frusemide } \\
\text { Placebo }\end{array}$ \\
\hline
\end{tabular}

restudied on a subsequent admission, making a total of 21 rotations. Eleven patients-cor pulmonale (3), ischaemic heart disease (3), renal failure (3), alcoholic cardiomyopathy (1), and rheumatic valvular disease (1) -who were still oedematous were then studied to assess the effects of prolonged administration. Three further control days were observed, following which bumetanide $1 \mathrm{mg}$ orally was administered for eight consecutive days. The 24-hour urinary volume and electrolyte excretion were measured daily. In addition to the effects of the drug on creatinine clearance, plasma electrolyte and acid-base status, serum uric acid, and blood sugar were studied. The patient's liver function, haematological status, and urine analysis were evaluated before and at the end of the study.

(c) A further five patients, in whom there was evidence of sodium retention and of whom two had diabetic glucose tolerance curves, were subsequently given $2 \mathrm{mg}$ of bumetanide daily for seven days. Glucose tolerance tests were performed before and on the seventh day of administration.

Biochemical Methods.- Sodium and potassium were measured by flame photometry (E.E.L. Model 150), chloride potentiometrically (E.L.C. Chloride Meter), acid-base by the Astrup technique, creatinine by a modification of the Jaffé method (Bittles et al., 1965), uric acid by a modification of the Folin method (Folin and Denis, 1912-13), liver enzymes by the Eskalab system, and glucose and urea with a Technicon AutoAnalyzer.

\section{Results}

\section{VOLUNTEER STUDIES}

The four volunteers were randomly given frusemide $80 \mathrm{mg}$ or bumetanide $0.5,1,2,3$, or $4 \mathrm{mg}$ at four-day intervals. Urine was collected hourly for two control periods and then halfhourly for five hours following the administration of the drug; the values for urinary volume and electrolyte excretion were compared with control days.

Fig. 2 shows the mean responses to the doses used; sodium and potassium only are illustrated, but chloride and water 
excretion were similar in configuration to that of sodium, chloruresis always exceeding natriuresis. Urinary bicarbonate was not measured in this study. It can be seen that natriuresis increases up to doses of $3 \mathrm{mg}$, no further response being observed with $4 \mathrm{mg}$. Potassium excretion was also increased but this was not dose-dependent. Frusemide $80 \mathrm{mg}$ seemed no more effective than bumetanide 1-2 mg. The shape of the sodium excretory response curve after oral bumetanide is shown in

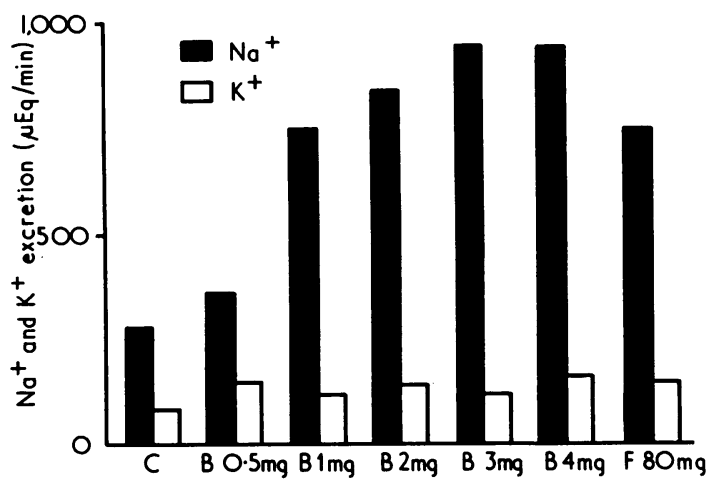

FIG. 2-Mean $\mathrm{Na}^{+}$and $\mathrm{K}^{+}$excretion in $\mu \mathrm{Eq} / \mathrm{min}$ over five hours in healthy volunteer. $\mathrm{B}=$ Bumetanide. $\mathrm{F}=$ Frusemide. $\mathbf{C}=$ Control.

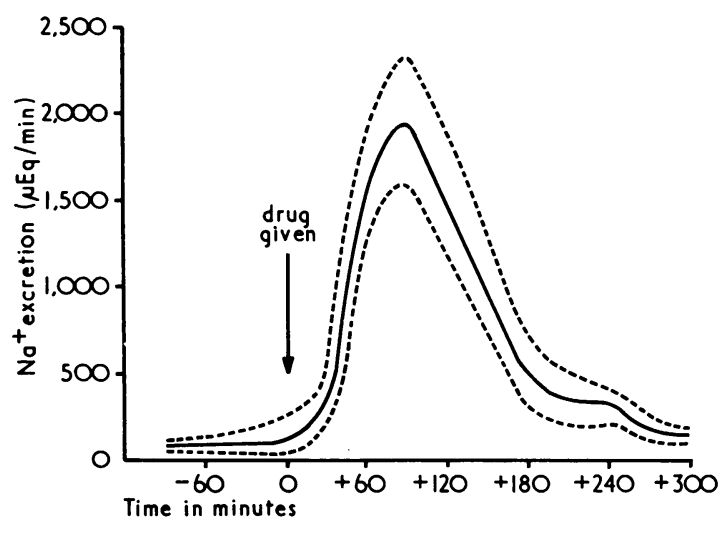

FIG. 3- $\mathrm{Na}$ + excretion in response to oral bumetanide (mean of all $1-\mathrm{mg}$ and $2-\mathrm{mg}$ dosages in healthy volunteers). The dotted lines represent the standard error.

Fig. 3. Onset of action is observed within 30 minutes, the peak occurring at 90 minutes with a return to baseline values at 270 minutes.

\section{PATIENT MATERIAL}

The effects of bumetanide 1 or $2 \mathrm{mg}$, frusemide 40 or $80 \mathrm{mg}$, and placebo 1 or 2 tablets respectively were studied in 18 oedematous patients, three of whom were restudied on a subsequent admission, making a total of 21 rotations using the random dosage schedule described above (Table I). The 24-hour urinary volumes and electrolyte contents were analysed statistically. The means are represented in Table II. It is clear that both treatments differ highly significantly from the placebo with respect to all criteria studied $(P<0.001)$. Also there is no apparent difference between the two treatments. However,

TABLE II-Mean Urinary Volumes and Electrolytes with Standard Deviations from 18 Oedematous Patients Treated according to the Rotations in Table

\begin{tabular}{|c|c|c|c|}
\hline & Placebo & Frusemide & Bumetanide \\
\hline $\begin{array}{l}\mathrm{Na}^{+}(\mathrm{mEq} / 24 \text { hours }) \\
\mathrm{Cl} \text { (mEq/24 hours) } \\
\mathrm{K}+\mathrm{mEq} / 24 \text { hours }) \\
\text { Volume (ml/24 hours) }\end{array}$ & $\begin{array}{r}55 \cdot 9 \pm 9.8 \\
41 \cdot 9 \pm 7 \cdot 7 \\
23.5 \pm 2 \cdot 1 \\
1,030 \pm 92\end{array}$ & $\begin{array}{c}144 \cdot 2 \pm 19 \cdot 4 \\
149 \cdot 7 \pm 19 \cdot 8 \\
37 \cdot 8 \pm 2 \cdot 6 \\
2,143 \pm 176\end{array}$ & $\begin{array}{r}154.9 \pm 17 \cdot 2 \\
152.9 \pm 17.6 \\
39.5 \pm 3.3 \\
2,194 \pm 197\end{array}$ \\
\hline
\end{tabular}

because for medical reasons some patients were given double doses of bumetanide or frusemide and because an analysis showed that the criteria (24-hour volumes, etc.) were not normally distributed variables, it was decided to confirm this by more rigorous statistical treatment in order to ensure unbiased estimates.

Adjustments for the effect of order of treatment and of dosage were calculated from the slopes of a linear regression of the variable in question on the two "independent" variables: $\mathrm{V}$, which is assigned the value -1 for the lower dose and +1 for the higher dose, and $V_{2}$, which is given the value -1 for the order frusemide/bumetanide, +1 for the order bumetanide/ frusemide, and 0 if placebo occurs on the second of the three days. An analysis showed that the logarithmic transformation of the $\mathrm{X}$-variable could be treated as normally distributed, greatly facilitating the construction of tests of significance. Furthermore, in order to cancel that part of the total variance caused by variation between patients, comparisons were performed by means of the difference $\mathrm{Y}=\left(\log \mathrm{X}_{\text {bumetanide }}-\log \mathrm{X}_{\text {frusemide }}\right)$, calculated for each patient individually.

The linear regressions showed positive slopes due to order of treatment for all four variables. All the slopes were greater than one standard deviation, and those for $\mathrm{Na}^{+}$and $\mathrm{Cl}^{-}$attain statistical significance at the $95 \%$ level. This shows that the treatment effect is smaller on the second of two consecutive treatment days. The slopes due to dosage are not significant. Table III lists the results expressed as ratios between the effects

TABLE III-Ratios between the Effect of Bumetanide and Frusemide (see Text) on 24-hour Urine Volume and Electrolyte Excretion. 95\% Confidence Limits are Given in Parentheses

$\begin{array}{llllllll}\text { Effect on volume } & \ldots & \ldots & \ldots & \ldots & \ldots & \ldots & 1.09(0.92-1.30) \\ \text { Effect on } \mathrm{Na}^{+} & \ldots & \ldots & \ldots & \ldots & \ldots & \ldots & 1.26(1.04=1.53) \\ \text { Effect on } \mathrm{K}^{+} & \ldots & \ldots & \ldots & \ldots & \ldots & \ldots & 1.00(0.82-1.22) \\ \text { Effect on } \mathrm{Cl}^{-} & \ldots & \ldots & \ldots & \ldots & \ldots & \ldots & 1.20(0.88=1.49) \\ \text { Effect on } \mathrm{Na}^{+} / \mathrm{K}^{+} & \ldots & . & \ldots & \ldots & \ldots & \ldots & 1.27(1.02-1.57)\end{array}$
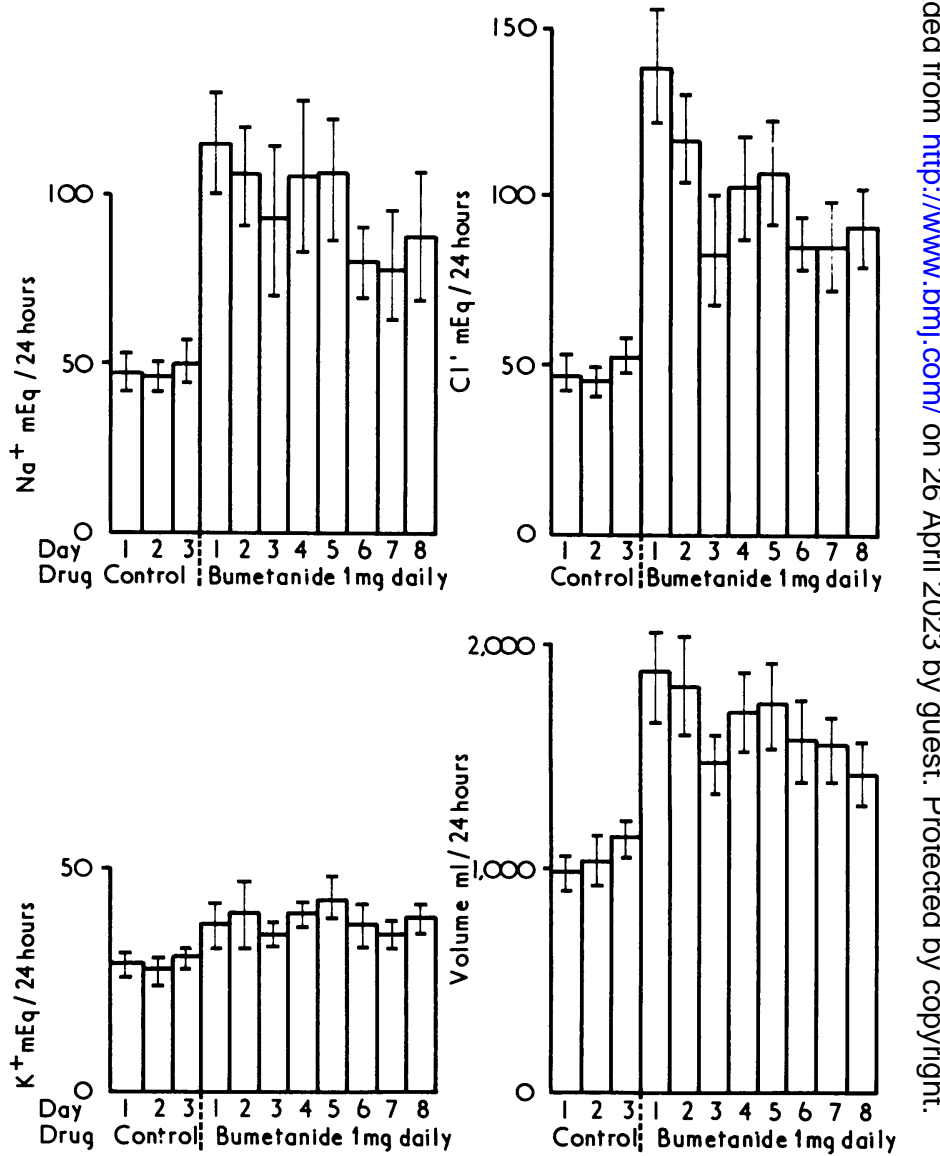

FIG. 4-Urinary volume and electrolyte excretion on three control days and eight treatment days (mean of 11 patients with standard deviation). 
of bumetanide and frusemide. It is apparent that the diuretic potency of 1 and $2 \mathrm{mg}$ of bumetamide is identical with that of 40 and $80 \mathrm{mg}$ of frusemide respectively.

Fig. 4 represents the 24-hour urinary $\mathrm{Na}^{+}, \mathrm{K}^{+}, \mathrm{Cl}^{-}$, and volume for three control days and eight consecutive treatment days with bumetanide. Of the 11 patients studied 10 were oedema-free before or by the end of the study. The mean increment in $\mathrm{Na}+$ excretion during the eight trial days was $100 \%$ over the control values, varying from $142 \%$ on Day 1 to $87 \%$ on Day 8 . In contrast potassium excretion increased by about $30 \%$ and did not vary significantly during the trial period. As in the acute studies, chloruresis seemed to exceed natriuresis initially but this effect was not maintained with continued administration.

At the end of eight days' continuous administration no significant changes had occurred in plasma electrolytes, bicarbonate, urea, and creatinine. The serum uric acid level rose slightly from a mean of $5.06 \pm 1.30$ to $5.75 \pm 0.9(0.025<P<0.05)$ (Table IV). The mean creatinine clearance for the control

TABLE IV-Biochemical Findings (expressed as mg/100 ml Plasma, Mean Values) on a Control Day and on the Eighth Day of Continuous Bumetanide Dosage

\begin{tabular}{|c|c|c|c|c|c|c|c|}
\hline & & & \multicolumn{2}{|c|}{ Pre-Drug Values } & \multicolumn{2}{|c|}{ After 8 Days Drug } & \multirow[b]{2}{*}{$\mathbf{P}$} \\
\hline & & & Mean & S.D. & Mean & S.D. & \\
\hline $\begin{array}{l}\text { Urea } \\
\text { Sodium } \\
\text { Potassium } \\
\text { Chloride } \\
\text { Creatinine } \\
\text { Bicarbonate. } \\
\text { Uric acid }\end{array}$ & $\begin{array}{l}\ldots \\
\cdots \\
\cdots \\
\cdots \\
\cdots\end{array}$ & $\begin{array}{l}\ldots \\
\cdots \\
\cdots \\
\cdots \\
\cdots\end{array}$ & $\begin{array}{c}57 \cdot 0 \\
135 \\
4 \cdot 25 \\
102 \cdot 6 \\
2 \cdot 02 \\
22 \cdot 8 \\
5 \cdot 06\end{array}$ & $\begin{array}{ll} \pm & 33.7 \\
\pm & 12.5 \\
\pm & 0.56 \\
\pm & 4 \cdot 2 \\
\pm & 1 \cdot 4 \\
\pm & 3.4 \\
\pm & 1.30\end{array}$ & $\begin{array}{c}59 \cdot 3 \\
135 \\
4 \cdot 28 \\
100 \\
1 \cdot 9 \\
23 \cdot 7 \\
5 \cdot 75\end{array}$ & $\begin{array}{ll} \pm & 31.5 \\
\pm & 4 \cdot 5 \\
\pm & 0.55 \\
\pm & 6 \cdot 1 \\
\pm & 1 \cdot 3 \\
\pm & 3.3 \\
\pm & 0.9\end{array}$ & $\begin{array}{l}\text { N.S. } \\
\text { N.S. } \\
\text { N.S. } \\
\text { N.S. } \\
\text { N.S. } \\
\text { N.S. } \\
<0.05\end{array}$ \\
\hline
\end{tabular}

N.S. = Not significant.

period was $33 \cdot 5 \pm 17$ and on the eighth trial day was $30 \cdot 4 \pm 15$ $(P>0 \cdot 3)$. Serum bilirubin, aspartate and alanine aminotransferase, alkaline phosphatase, blood glucose, complete blood count, and urine analysis with microscopy were unaffected by continuous administration of bumetanide for eight days. No serious side effects or toxic manifestations were noted. The only adverse effect noted was the occurrence of abdominal discomfort in one patient on two separate occasions within one hour of taking the drug. This was not seen with the placebo. Because of this intolerance the patient's participation in the trial was discontinued.

\section{Discussion}

Bumetanide was found to be similar in onset, peak, and duration of action to frusemide in normal subjects (Fig. 2), but at about one-fortieth the molar dosage. It seemed reasonable, therefore, to compare the efficacy and potency of these drugs with each other and with a placebo in oedematous patients. Since the effect of a diuretic varies according to the patients' pathophysiological status, the day of administration, and the compound administered, the patients were allocated randomly to the dosage schedule shown in Table $I$ in order to reduce the variance. This permitted a comparison of the individual agents independent of the other variables. The data subjected to a statistical analysis indicated that bumetanide 1 and $2 \mathrm{mg}$ was equipotent with frusemide 40 and $80 \mathrm{mg}$ respectively with regard to urinary excretion of sodium, chloride, potassium, and water.
Improved diuretic efficacy and resultant extended survival increases rather than decreases the problems of management of oedema (Walker, 1966). Therefore, despite the introduction of potent agents such as ethacrynic acid and frusemide, many considerations justify the development of newer pharmacological agents to promote renal sodium loss. Refractoriness to one diuretic may sometimes be readily overcome by the use of a different drug. Some of the patients in the present study responded poorly to frusemide $80 \mathrm{mg}$ but had a brisk diuresis with bumetanide $2 \mathrm{mg}$.

It has been recently pointed out that at very low glomerular filtration rates massive doses of frusemide may be required (Maher and Schreiner, 1965). Since frusemide is excreted competitively through a transport pathway (Hook and Williamson, 1965) which under these circumstances is partially saturated (Bourke et al., 1970), potential side effects as yet undocumented, such as increased organic anion retention, would seem likely.

Bumetanide appears equally as effective as frusemide in chronic renal failure (creatinine clearance $5-20 \mathrm{ml} / \mathrm{min}$ ). The markedly lower dosage on a weight basis, however, could be a considerable advantage. Many diuretics cause hyperuricaemia (Lyon and DeGraff, 1964; Russell et al., 1968) due to their sharing a common secretory pathway in the renal tubule. A slight but significant rise in serum uric acid was also observed with bumetanide in this study.

Like both frusemide and ethacrynic acid (Bourke et al., 1965; Laragh et al., 1966) bumetanide in acute studies tended to produce a greater chloruresis than natriuresis. Unlike these agents, however, this effect was not maintained with continuous administration and there was no fall in plasma chloride. It is also of interest that, in contrast to both frusemide and ethacrynic acid (Bourke et al., 1965), plasma bicarbonate was unaltered. Significant hypokalaemia was not observed in the present study, possibly due in part to the lack of alteration in plasma bicarbonate. Urinary potassium loss, nevertheless, was similar to that observed with frusemide.

We wish to thank the Biomedical Trust for generous support. We thank Dr. J. Masterson, Leo Laboratories, for supplies of bumetanide.

\section{References}

Bittles, A. H., Bell, J. F., and Neill, D. W. (1965). Fournal of Clinical Pathology, 18, 377 .

Bourke, E. Asbury, M. J., and O'Sullivan, S., (1972). In press.

Bourke, E., Counihan, T. B., Keelan, P., and Ryan, M. (1965). fournal of the Irish Medical Association, 56, 1 .

Bourke, E., Frindt, G., Preuss, H., Rose, E., and Schreiner, G. E. (1970). Clinical Science, 38, 41.

Brenner, B. M., Bennett, C. M., and Berliner, R. W. (1968). fournal of

Clinical Investigation, 47, 1358 .
Brenner, B. M., Keimowitz, R. I., Wright, F. S., and Berliner, R. W. (1969). fournal of Clinical Investigation, 48, 290.

Feit, P. (1971). Fournal of Medicinal and Pharmaceutical Chemistry, 14, 432. Folin, O., and Denis, W. (1912-13). Fournal of Biological Chemistry, 13,

469 .
Hook, J. B., and Williamson, H. E. (1965). Fournal of Pharmacology and Experimental Therapeutics, $149,404$.

Laragh, J. H., Cannon, P. J., Stason, W. B., and Heinemann, H. O. (1966). Annals of the New York Academy of Sciences, 139, 453.

Lyon, A. F., and DeGraff, A. C. (1964). American Heart fournal, 68, 710. Maher, J. F., and Schreiner, G. E. (1965). Annals of Internal Medicine, 62, 15 .

Russell, R. P., Lindeman, R. D., and Prescott, L. F. (1968). fournal of the American Medical Association, 205, 11.

Walker, W. G. (1966). Annals of the New York Academy of Sciences, 139, 481. 